\title{
MONITORING OF SEEPAGES IN EARTHEN DAMS AND LEVEES
}

\author{
F. ČEJKA ${ }^{1}$, V. BENEŠ ${ }^{2}$, F. GLAC ${ }^{3} \&$ Z. BOUKALOVÁ ${ }^{1}$ \\ ${ }^{1}$ VODNÍ ZDROJE, a.s., Czech Republic \\ ${ }^{2} \mathrm{G}$ IMPULS Praha spol. s r.o., Czech Republic \\ ${ }^{3}$ IL FAUT s r.o., Czech Republic
}

\begin{abstract}
The aim of this article is to describe an innovation in the monitoring of performance of earth embankments, namely the use of sensing systems for full-time monitoring of dam and levee seepages. The monitoring system being developed by the companies VODNI ZDROJE (Czech Republic) and EGIS (Republic of Korea) within the EUREKA project Short Term Assessment and Mitigation of Flood Risks is based on the measurement of temperature changes in the embankment body by using the discrete and distributed temperature sensors. The article provides an overview of the activities performed at the reservoir earth dam in pilot site Vlčkovice v Podkrkonoší and describes the (i) preliminary activities necessary for the proper spatial distribution of sensors in the embankment body including the geophysical and geotechnical survey and (ii) collection and evaluation of the data.

Keywords: fibre optic distributed temperature sensors, flood risk assessment, geophysical monitoring system, levee management, seepage monitoring
\end{abstract}

\section{INTRODUCTION}

The risk for European population originating from possible failure of dams and structures designed for flood control (further referred to as embankments) is widespread throughout Europe. In many countries, the number of small dams (up to $15 \mathrm{~m}$ of height) significantly exceeds the number of the large ones. For instance, in the UK the humble earthen flood embankments are by far the most ubiquitous flood risk management assets along the coast and watercourses as stated by Normandale [1].

Diverse sensor types have been used for the monitoring of stability and seepage regime in large dams for decades. In recent years, however, the development in the field of information and communication technologies (ICT) and sensing technologies has facilitated their use for the monitoring of small earth accumulation and flood embankments. The use of fibre optic distributed temperature sensors (FO DTS) is regarded as having a great potential in embankment monitoring. In this area, research was conducted by Khan et al. [2] on the automatic detection of singularities (seepage flows) within a trial embankment using optical timedomain reflectometry. In a laboratory experiment, Huaizhi and Yeyuan [3] dealt with seepage detection including the evaluation of seepage intensity based on double-line and single-line heat source data analysis.

Experimental application of FO DTS on real dams is reported, among others, by Pyayt et al. [4] in the project FP7 Urban Flood including dams on the Rhine (Germany) and in Boston (UK). On the Rhine dam, real seepage flows were monitored using the FO DTS systems. Research teams from AGH University of Science and Technology in Cracow are dealing with further installations and data evaluations from FO DTS systems on a research polygon [5, 6].

The Short Term Assessment and Mitigation of Flood Risks (STAMFOR) project was focused on real site implementation of an innovative embankment safety monitoring 
system for full-time monitoring of embankment seepage flows by temperature sensing systems. The main objective of the project was not only to confirm the effectiveness of these sensing systems, which had been sufficiently accomplished in similar past projects (see above), but especially to integrate the installation of the sensing systems into the existing safety supervision procedures for earth embankments. The design of the spatial distribution of the sensors is obviously a vital precondition for collecting reliable data from the sensing systems. Such a design can only be made based on a comprehensive interpretation of historic and, if needed, additional surveys of the site. For these purposes, STAMFOR methodology was developed as part of the project to describe all the activities necessary for a successful design and implementation of the sensing systems including subsequent data evaluation.

\section{STAMFOR METHODOLOGY}

The STAMFOR methodology describes all the steps needed for a successful implementation of the temperature sensing technology. These include especially the operations associated with the site reconnaissance survey, the design of the sensing system distribution pattern, and the installation and setting of the system. The entire methodology can be divided into the following sequence:

I. Research of available data sources includes the collection and analysis of available information on the area of interest.

II. Indirect survey is used to locate the reference and/or anomalous areas that are suitable for long-term monitoring by the STAMFOR technology. It provides data for a preliminary description of the embankment body as well as for a preliminary location of the monitoring profiles. Within the STAMFOR methodology, the indirect survey methods include a geophysical investigation to locate the reference as well as anomalous embankment sections that are suitable or practical for long-term monitoring. A convenient investigation method is the application of the geophysical monitoring system (GMS) according to Boukalová and Beneš et al. [7, 8], as described in an article [9] as part of the STAMFOR project.

III. Direct survey using boreholes and pits provides detailed information particularly on the vertical structure of the embankment body in the reference and/or anomalous areas located in the previous step.

IV. Final interpretation and design provides information for precise positioning of the sensing technology in the embankment body based on expert multidisciplinary assessment and calculations of the embankment body model.

V. Implementation stage comprises all the operations necessary for an effective installation of the selected sensing technology, further for launching the STAMFOR system pilot and, after the calibration is done, the full operation stage.

It must be stressed that each step mentioned above forms an integral part of the STAMFOR system application methodology and needs to be carried out in a sufficiently qualified way to ensure the validity and relevance of the output information gathered from the sensing systems.

Based on the STAMFOR methodology, a general design for the positioning of the sensing systems in the embankment body was made (Fig. 1), which was further verified by pilot measurements on the site of Vlčkovice v Podkrkonoší. 


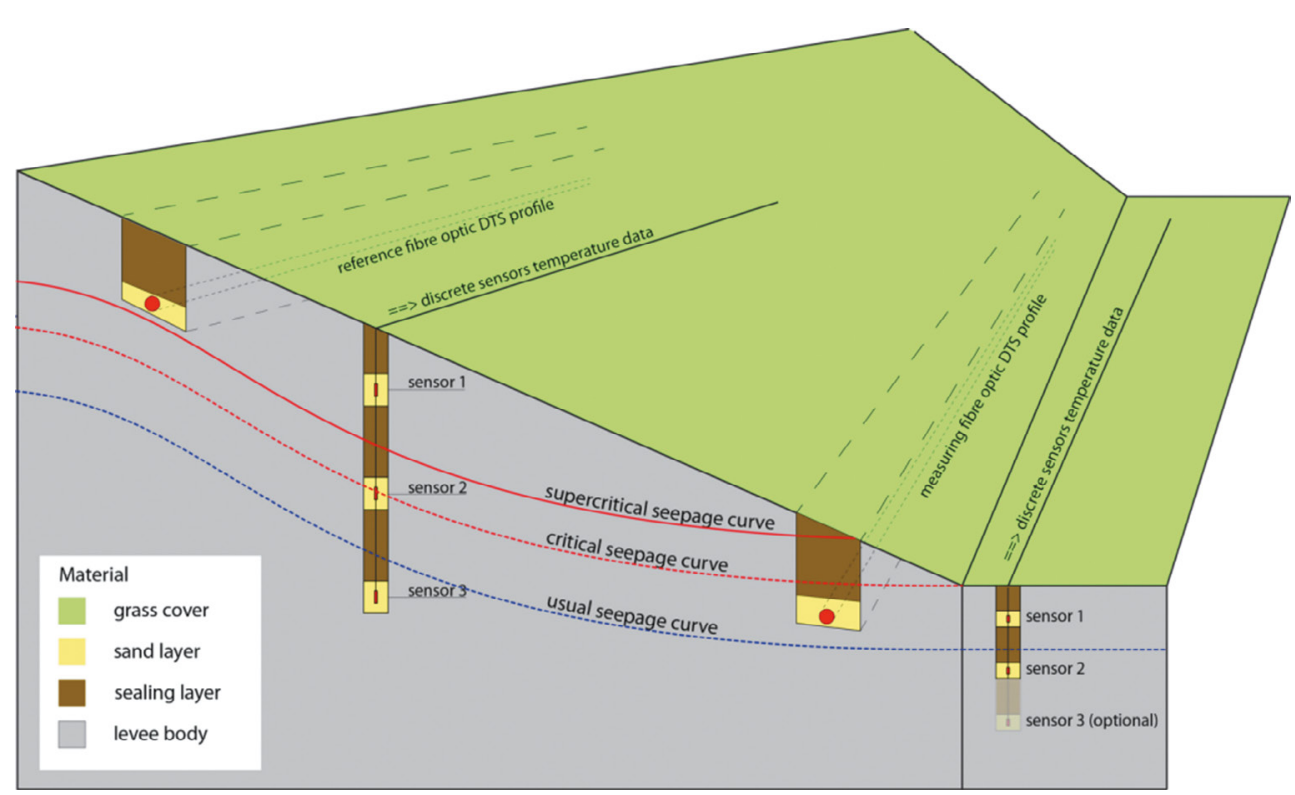

Figure 1: General spatial design of discrete and distributed sensors in the levee body.

\section{PILOT INSTALLATION ON THE SITE OF VLČKOVICE V PODKRKONOŠÍ}

In the project, the research was focused on two independent sensing systems - (1) borehole discrete temperature sensors (BDTS) and (2) FO DTS. For the pilot measurement, an earth dam of the Vlčkovice pond in Vlčkovice v Podkrkonoší having a height of $7 \mathrm{~m}$ (dam crest is located at approx. $299 \mathrm{~m}$ above sea level) and a length of $70 \mathrm{~m}$ was used. This pilot site was chosen mainly because there is a considerable seepage zone approximately at the midpoint of the height of the embankment body. Simple control over the water level of the pond enabled to activate and inactivate the seepage to monitor reactions of the sensors to the changes thus induced.

After the operations according to steps I and II of the STAMFOR methodology were carried out, monitoring profiles PF1 and PF2 (Fig. 2) were designed. Subsequently, step III was undertaken consisting in laying out and performing 4 core boreholes to determine the material composition within the embankment body. At each profile, the boreholes were drilled to a depth of approximately $11 \mathrm{~m}$ near the dam crest and to depths of $3.5 \mathrm{~m}$ and $6 \mathrm{~m}$, respectively, at the dam toe. Based on core sampling and the determined geomechanical properties, a seepage model of the dam was then calculated in step IV and exact depths for the positioning of the sensing systems were suggested (Fig. 3). After the exploratory boreholes were cased and equipped with water-level probes, they were used for direct monitoring of water-level fluctuations within the embankment body. This control system served for the verification of data gathered from the two measurement systems. Figure 3 gives a layout of the sensor arrangement.

The identification and exact depths of the point temperature sensors at profiles PF1 and PF2 are as follows:

\section{PF1}

- MVT1_1, downstream face, temperature sensors at 1.4, 3.4 and $4.8 \mathrm{~m} \mathrm{bgl}$

- MVT1_2, dam toe, temperature sensors at 1.8 and $2.9 \mathrm{~m} \mathrm{bgl}$ 


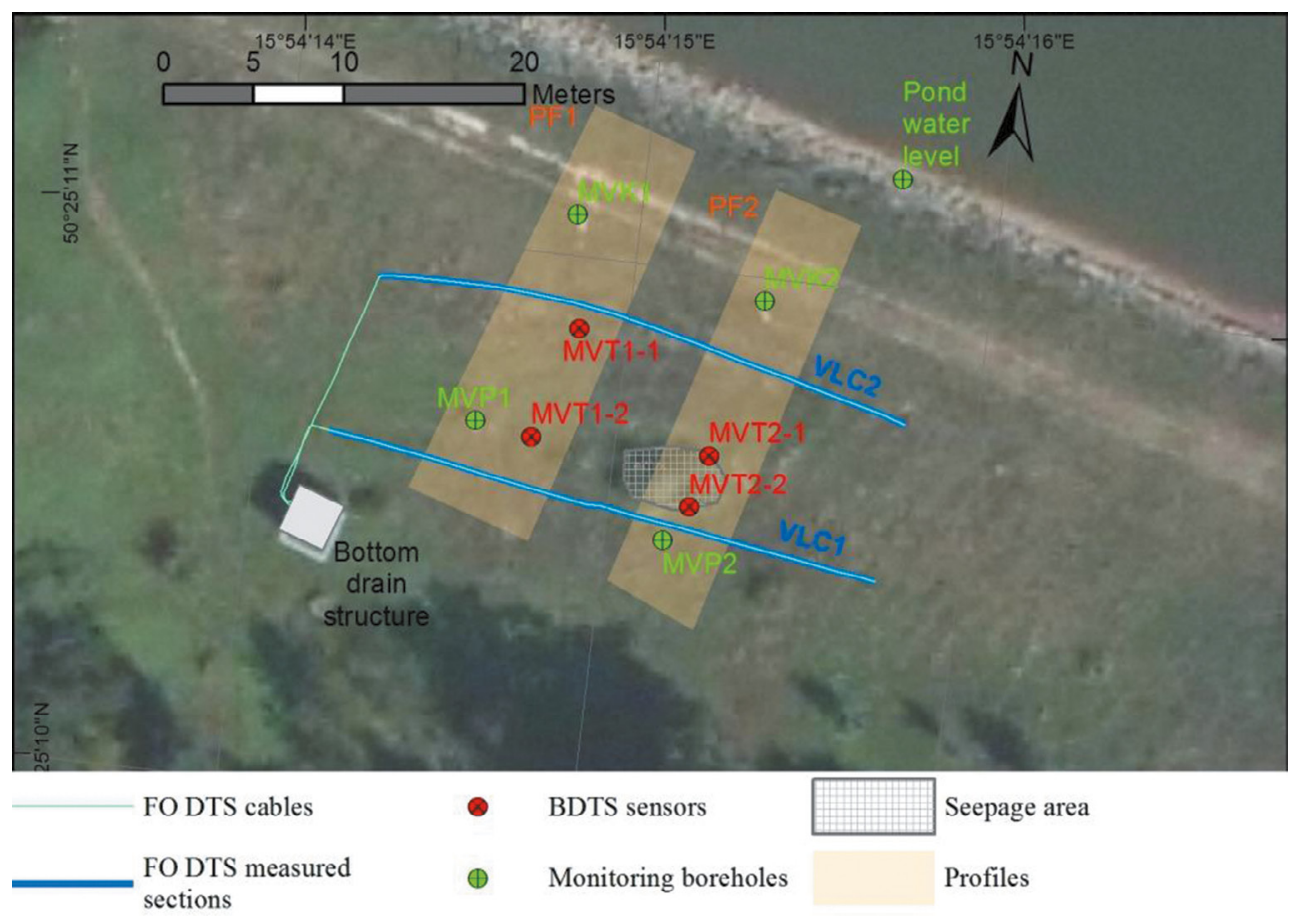

Figure 2: Positioning of the measurement equipment at the pilot site.

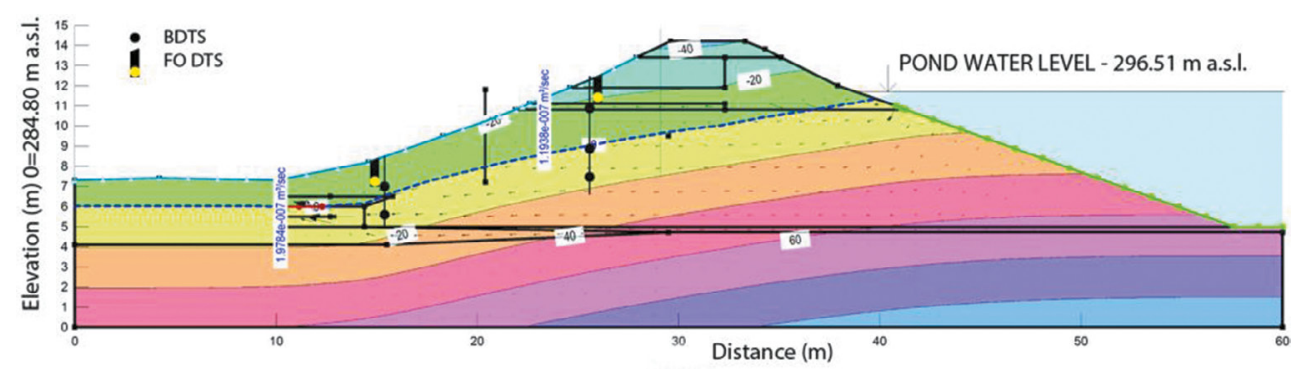

Figure 3: Seepage model of the dam body with depth indications for the positioning of point.

\section{PF2}

- MVT2_1, downstream face, temperature sensors at 1.0, 1.8 and $2.4 \mathrm{~m} \mathrm{bgl}$

- MVT2_2, dam toe, temperature sensors at 1.5 and $2.9 \mathrm{~m} \mathrm{bgl}$

The FO DTS cable lines were placed along the embankment body in two profiles (VLC1 and VLC2). VLC1 was directed through a seepage zone and used as a measurement profile, while VLC2 served as a reference profile. For protection, the cables were placed in a sand bedding of $20 \mathrm{~cm}$ in ditches $80-\mathrm{cm}$ deep. Then they were covered with a $30-\mathrm{cm}$ layer of compacted gravel of a $0 / 32 \mathrm{~mm}$ size and backfilled with the previously excavated earth, which 
was again compacted to minimize the impact of rainfall. On request of the dam manager, both profiles were sloped down in the western direction (further referred to as 'to the left') to drain off leaking water. This appeared to be an important aspect in the data evaluation stage (Sect. 4.3).

\section{EVALUATION OF DATA FROM THE PILOT MEASUREMENT}

After the installation of the BDTS system, the pilot trial was started on 06 October 2015 by emptying the Vlckkovice reservoir, which caused the water level to drop below the level critical for the activation of the seepage. From this moment, data on water-level and temperature fluctuations both in the reservoir and in the monitoring boreholes, further on air temperature, precipitation and temperature at each point temperature sensor were recorded in a 20-min step. In February 2016, the installation of the FO DTS cables was finished and data collection was started using a 5-min step.

The evaluation of the data from the BDTS system pilot measurement was done for the period of November 2015-March 2016, during which the water level in the reservoir rose beyond the critical level and thus the seepage was activated.

The evaluation of the data from the FO DTS system pilot measurement was done for the period of February 2016-October 2016, during which the water level again dropped below the critical level due to dry summer and thus the seepage was deactivated.

The following paragraphs give the measurement results of both the control system and the two measurement systems.

\subsection{Measurement of the seepage conditions in the monitoring boreholes - control system}

The water-level fluctuation curves for the monitoring boreholes reflect the water level changes in the reservoir. These reactions can be seen both at the dam crest and at the dam toe.

The analysis of the dependence of water levels in the monitoring boreholes on the pond water levels (Fig. 4) clearly shows that the dependence rate is not constant but significantly shifts at three height levels. Once the water level in the reservoir rises beyond approximately $296.64 \mathrm{~m}$ a.s.1., water level in profile PF2 starts to rise more rapidly. This rise becomes even more rapid, once the pond water level exceeds $296.88 \mathrm{~m}$ a.s.l., and continues until the pond water level reaches $297.10 \mathrm{~m}$ a.s.l.

From this point on, the reaction of profile PF2 decreases, while in profile PF1, a nearly steady rise continues from pond water level $=297.20 \mathrm{~m}$ a.s.l. These findings correspond to the occurrence of seepage zones observed on the downstream face of the dam, the results of the geotechnical investigation as well as the seepage model projections concerning the existence of permeable layers at $296.70 \mathrm{~m}$ a.s.l. The pond water level exceeded this critical level on 07 December 2015. On 21 December 2015 (pond water level at $297.34 \mathrm{~m}$ a.s.1.), an already fully developed seepage zone was observed on the downstream face of the dam during visual site inspection. On 10 July 2016, the pond water level again dropped below $296.70 \mathrm{~m}$ a.s.l.

\subsection{BDTS system data evaluation}

For BDTS system data analysis, the data from the period of 31 October 2015 to 31 March 2016 were collected.

We assume that if the dam is in an equilibrium state (without seepage or water-level fluctuations within the dam), the temperature changes of the temperature sensors in the dam 


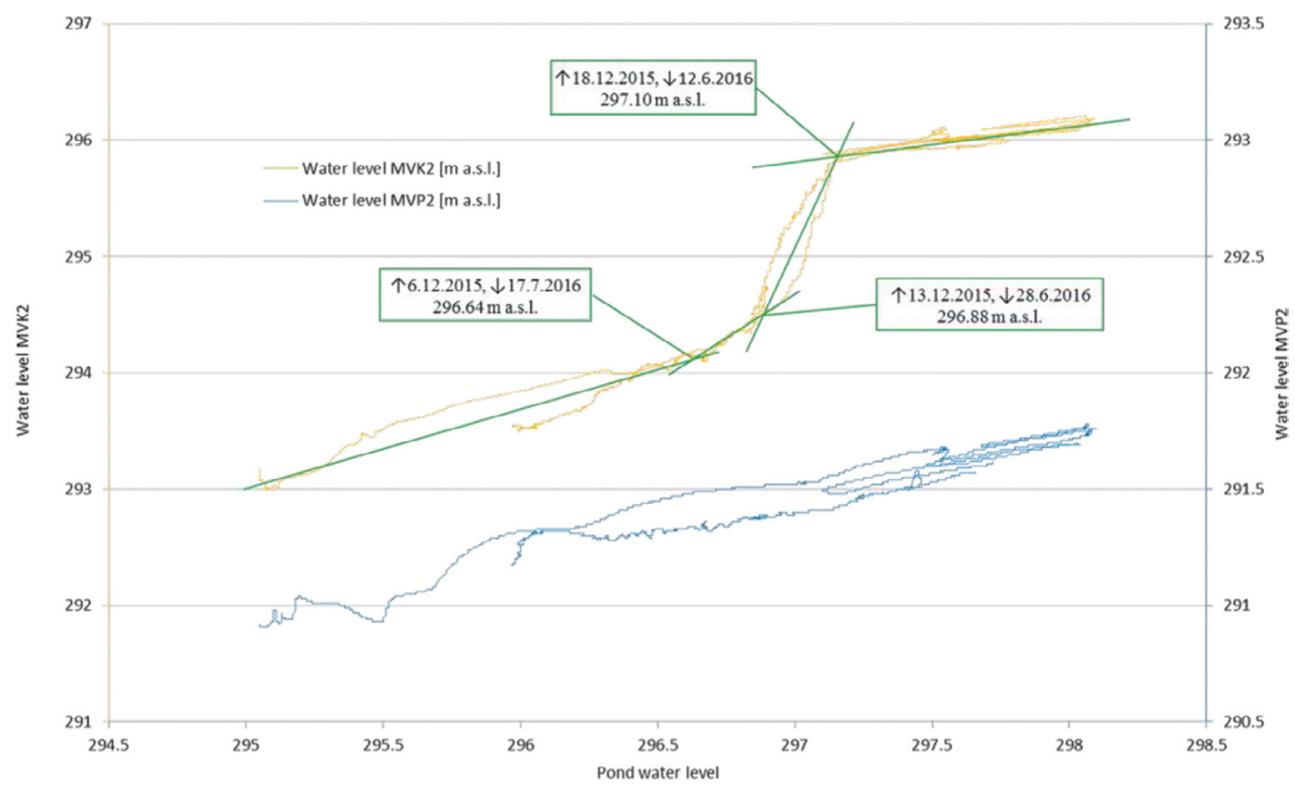

Figure 4: Dependence of water levels in the monitoring boreholes (profile PF2) on the pond water levels.

are influenced by air temperature (or water in the pond) and heat flux from Earth's interior (which we consider to be constant for our purposes). In case of an equilibrium state, the total rate of change (derivative) in the temperature behaviour as well as the amplitude of the local anomalies thus corresponds to atmospheric (climatic) influences and their intensity decreases with depth. Temperature changes spread from the surface to the depth with a time delay. Therefore, it is necessary to make a time shift for the temperature curves for analysis. The magnitude of the shift is to be determined based on the depth of each temperature sensor.

A deviation from the temperature behaviour in the dam body as described above may indicate a seepage flow (that is a water-level change within the dam), if such deviation shows a direction of change congruent with the temperature gradient between the existing sensor temperature and the temperature of water in the reservoir. If, on the other hand, such deviation has an opposite direction, it may be caused, e.g., by a change in groundwater level. In most cases, groundwater has a significantly different temperature from that of the pond water. It may also be a false anomaly, caused, e.g., by percolation of rainwater towards the sensor.

In this article, the sensors in boreholes MVT1_2 and MVT2_2 were used for the evaluation.

\subsubsection{Evaluation of data from MVT1_2 sensors}

In borehole MVT1_2, two temperature sensors at depths of $2.9 \mathrm{~m} \mathrm{bgl}$ (measuring sensor) and $1.8 \mathrm{~m} \mathrm{bgl}$ (reference sensor) were installed.

To adjust the temperature response of the measurement sensor to the reference sensor, to air temperature and seepage conditions in the dam (Fig. 5), an optimal correlation was found by shifting the time series forward by 3 days (reference sensor MVT1_2-1.8 m) and 20 days (air temperature sensor). The air temperature data were smoothed out by a moving average method using 255 hour-series. 


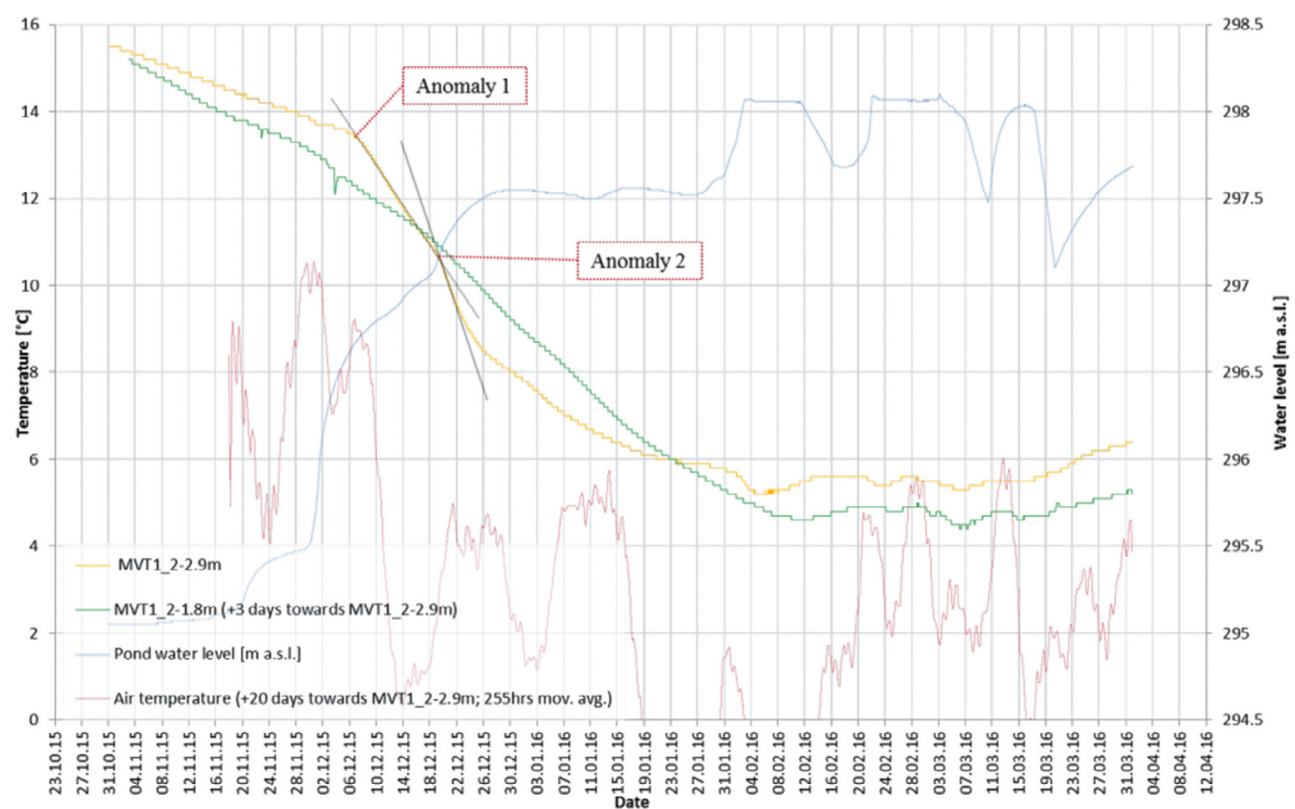

Figure 5: Comparison of the temperature time series in borehole MVT1_2 (sensors at 1.8 and $2.9 \mathrm{~m} \mathrm{bgl}$ ), air temperature and pond water level.

In the measurement sensor data series, two sharp deviations were found where the measurement sensor temperature data trend significantly diverged from that of the reference sensor (this sensor is assumed to be influenced by air temperature fluctuations). The first anomaly took place on 06 December 2015 at pond water level $=296.6 \mathrm{~m}$ a.s.l., the second on 19 December 2015 at pond water level $=297.15 \mathrm{~m}$ a.s. 1 .

It is assumed that the first anomaly was caused by a reactivation of the seepage regime in the dam after a long period of drought. At that time, the standard seepage curve reached the rock toe area of the dam.

The second anomaly may be attributed to an intensification of the seepage condition in the dam body, associated also with the observed seepage zone on the downstream face of the dam.

\subsubsection{Evaluation of data from MVT2_2 sensors}

In borehole MVT2_2, two temperature sensors at depths of $2.9 \mathrm{~m} \mathrm{bgl}$ (measuring sensor) and $1.5 \mathrm{~m} \mathrm{bgl}$ (reference sensor) were installed.

In this case, time shift was done only for air temperature (+20 days, smoothed out by a moving average using 255-h time series) to preserve the time-temperature dependences recorded by the BDT sensors. Additionally, pond water temperature fluctuations were included in the visualization of the measured data (Fig. 6).

In the measurement sensor data series, two sharp deviations were again found. In borehole MVT2_2 (located below the active seepage zone - see Fig. 2), the anomalies were detected at the measurement sensor on 01 December 2015 at pond water level $=295.7 \mathrm{~m}$ a.s.l., and on 03 December 2015 at pond water level $=296.4 \mathrm{~m}$ a.s.l. The first case may be accounted for 


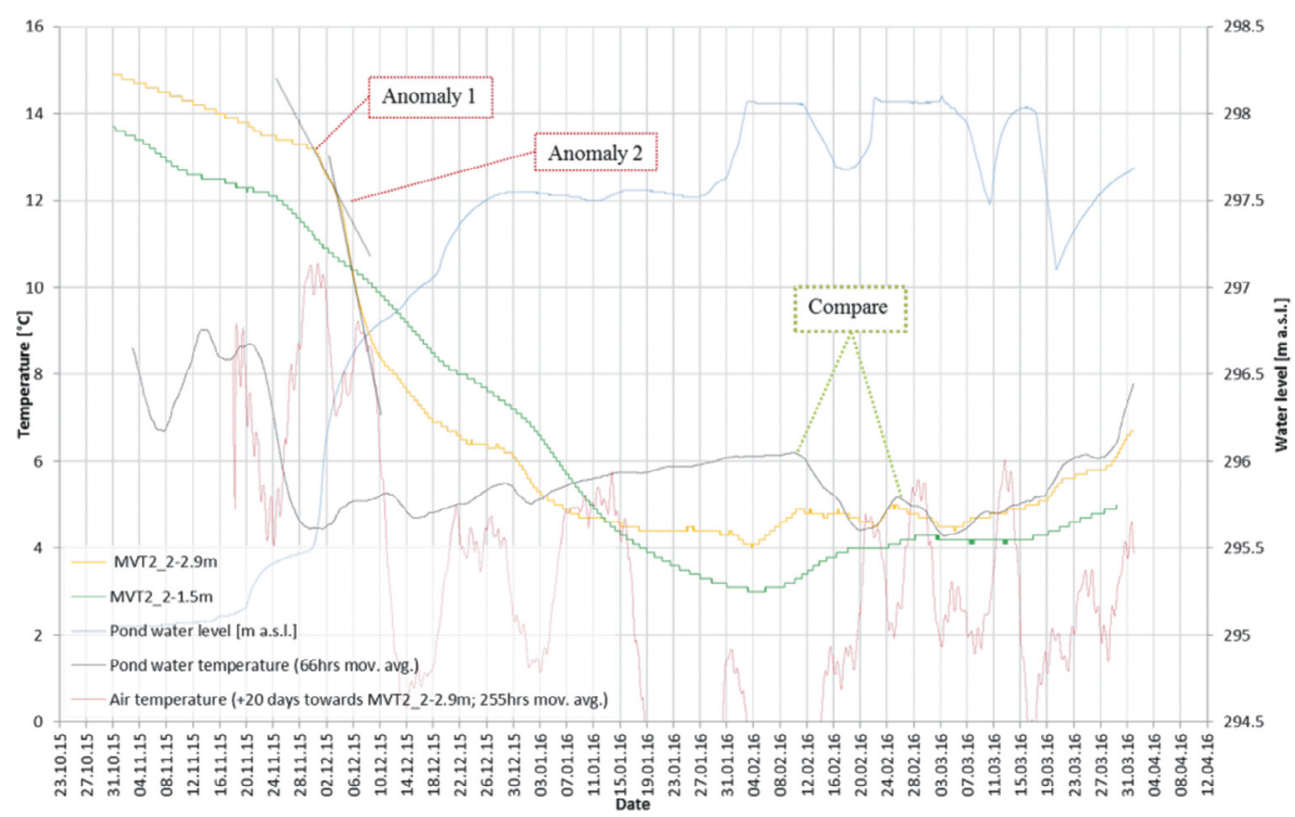

Figure 6: Comparison of the temperature time series in borehole MVT2_2 (sensors at 1.5 and $2.9 \mathrm{~m} \mathrm{bgl}$ ), air temperature, pond water temperature and pond water level.

by an activation of the usual seepage regime in the dam (note the quick response to the pond water-level rise). The second sharp deviation indicates a more intense flow of the cooler pond water, as it reached a permeable layer.

To comprehend the complexity of the investigated dependences (the explanation of which exceeds the scope of this article), compare the influences of pond water temperature and air temperature in the periods of 04-08 February 2016 and 24-28 February 2016, respectively (compare the temperatures of MVT2_2-2.9 m, air and pond water).

The comparison between the interpreted temperatures in boreholes MVT1_2 and MVT2_2 shows that in the MVT2_2 area, seepage appears considerably sooner and at lower pond water level. This fact corresponds to the existence of observed seepage zones on the downstream face of the dam in the proximity of this borehole.

\subsection{Evaluation of data from the FO DTS system}

Passive temperature measurements at VLC1 and VLC2 profiles were started on 12 February 2016 after a series of calibrations were carried out until the end of October 2016. The measurements using optical fibre cables did not coincide with the rise in water level in the Vlckkovický pond and the activation of seepage in December 2015. However, it did coincide with the inverse phenomenon, that is the water-level decline, which was caused by low precipitation in the spring and summer months of 2016, and thus with the deactivation of seepage in July 2016.

The data evaluation showed that for almost the entire period (with the exception of the 'temperature shift', see below) an anomalous behaviour of the left part of monitoring 
profile VLC1 took place that was relatively sharply delimited on the right. This behaviour was in contrast with that of the reference profile VLC2, which was consistent over the entire length and the whole measurement period. This anomalous behaviour was caused by a seepage flow occurring above VLC1 profile at local chainage 16-22. On the dam's manager request that the FO DTS profiles should also work as drains, the ditches were sloped in the direction to the lower local chainage (to the left). As a result, we can see a sharp delimitation of the seepage zone on the right side, while to the left the spatial delimitation of the seepage is blurred by water flowing along the preferential pathway of the drain containing the optical cable.

In the interpretation of data gathered from the FO DTS as well as BDTS systems, the interdependences between the pond water temperature, air temperature and the temperature of the dam body should always be kept in mind. Taking into consideration these facts, the four following indications of seepage could be identified on the site during the measurement period:

1. In winter (12-29 February 2016), water seeping through the dam body warmed up the relatively cooler dam body (Fig. 7)

2. In the period of the 'temperature shift' (at the beginning of April 2016 in our case - Fig. 8), the temperature of the saturated zone (influenced for the most part by pond water temperature) and that of the unsaturated zone (influenced for the most part by air temperature and the sun) come into balance.

3. In summer (Fig. 9), water seeping through the dam body cools down the relatively warmer body/surface of the dam.

4. The seepage was vanishing in the summer of 2016, when the pond water level was gradually declining due to low precipitation until it reached the critical level for the deactivation of the seepage. The measurement data show gradual disappearance of the described anomaly on the left side of profile VLC1 (Fig. 10), likely caused by the ceasing seepage flow. The turning point for the deactivation of the seepage appears to be the period between 25 and 30 July 2016, corresponding to pond water level $=296.5 \mathrm{~m}$ a.s.1.
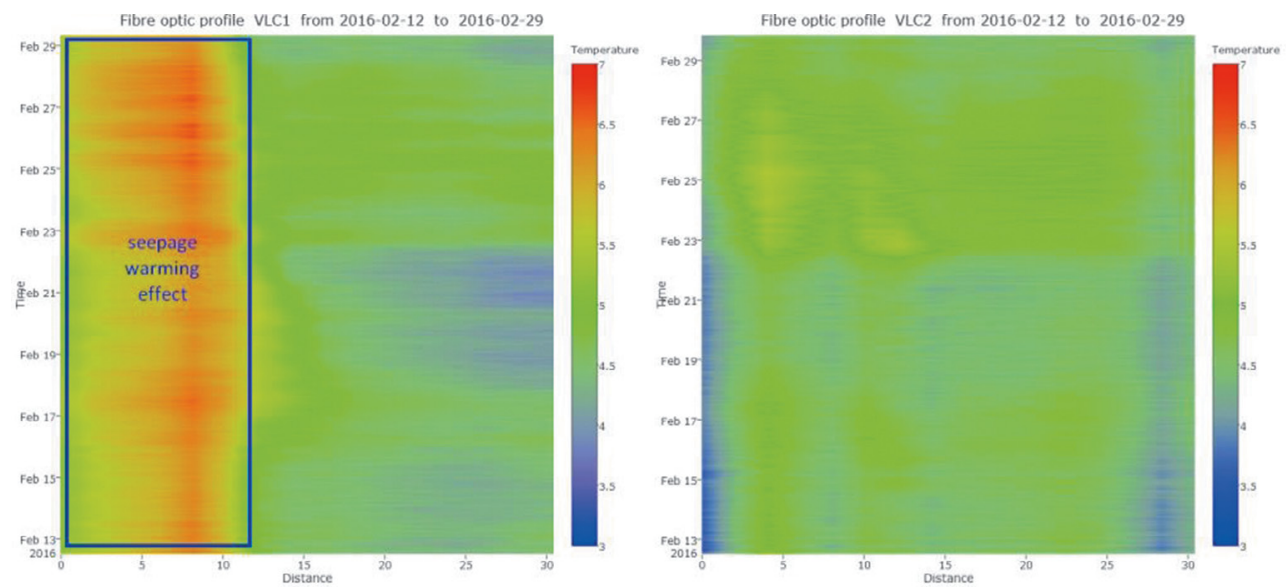

Figure 7: Comparison of FO DTS measurement and reference profiles in winter. 


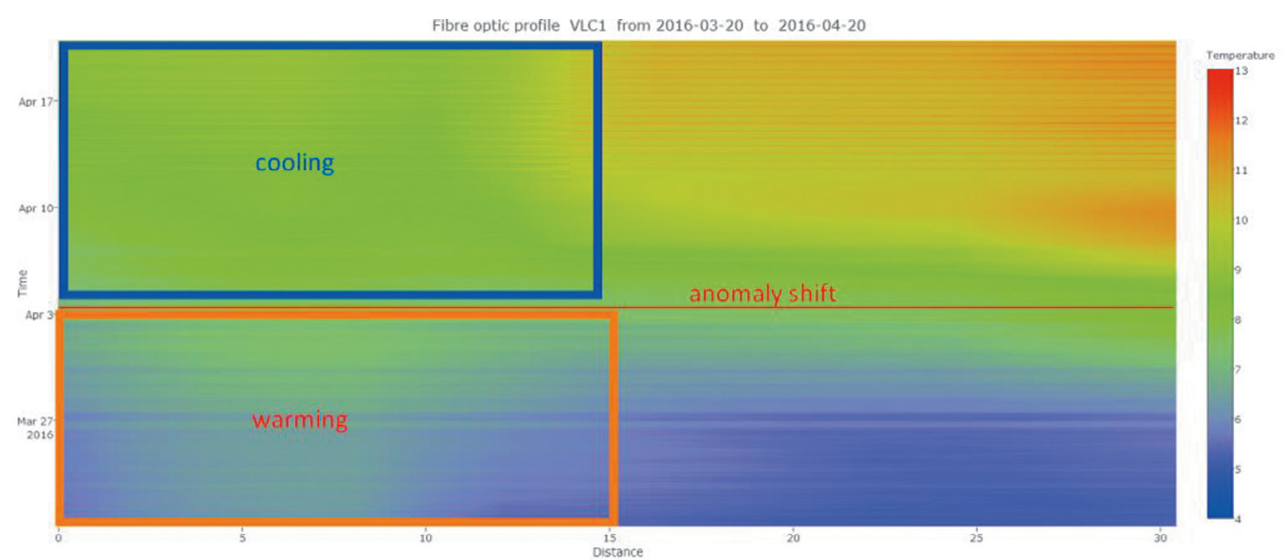

Figure 8: Measurement profile data visualization in the period of 'temperature shift'.
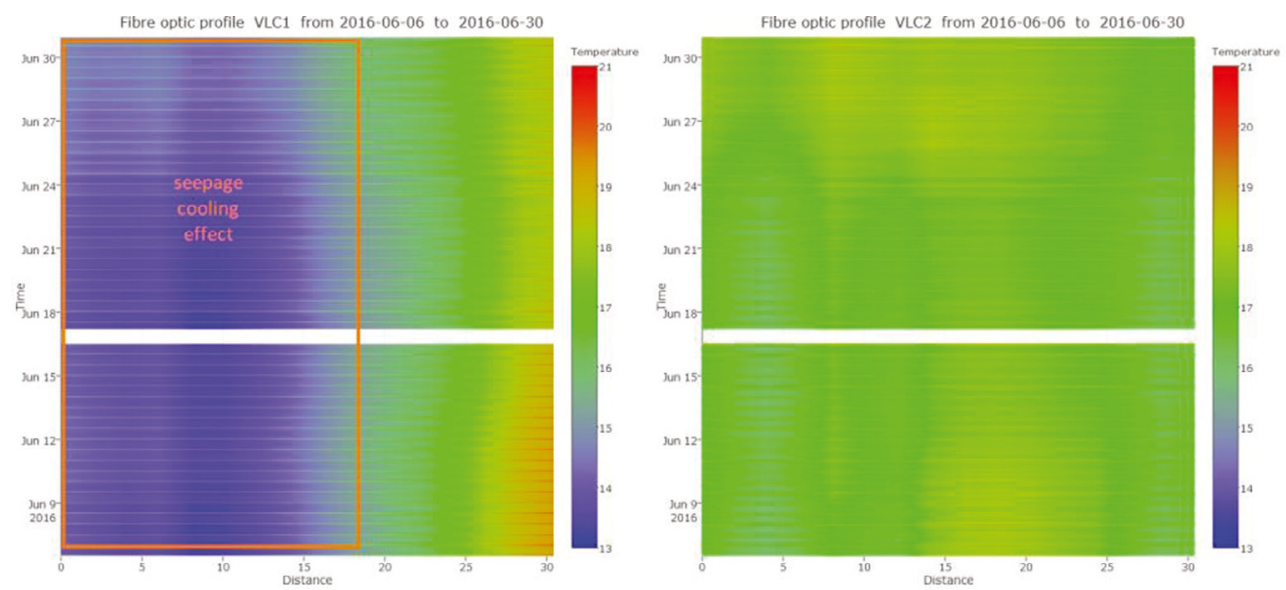

Figure 9: Comparison of FO DTS measurement and reference profiles in summer.
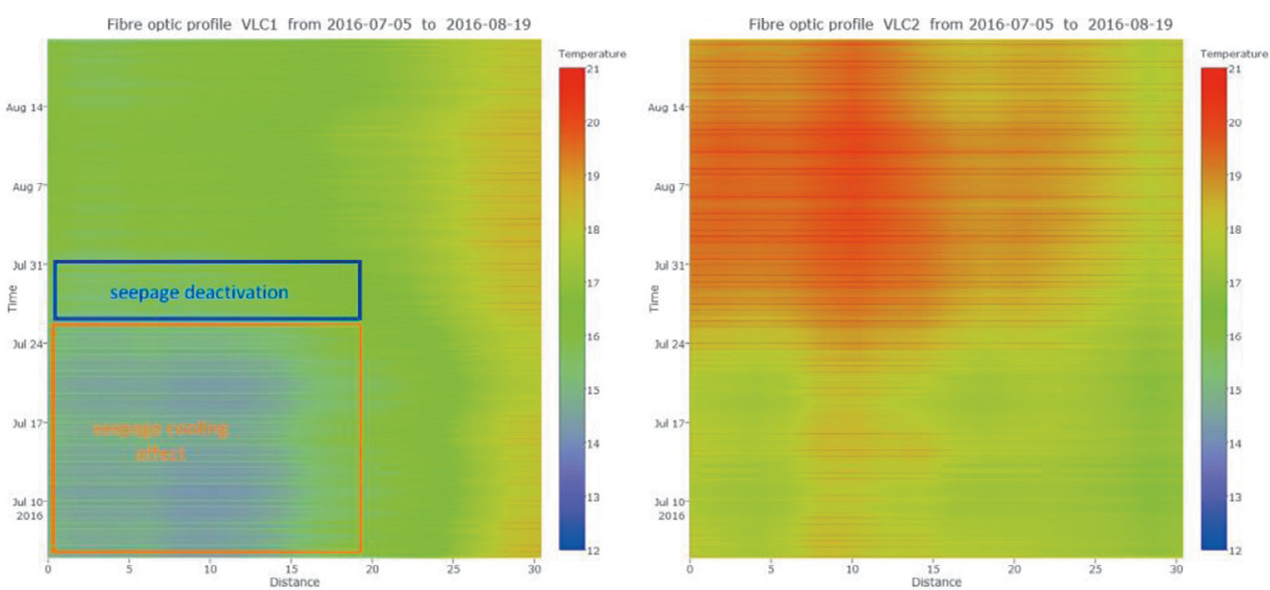

Figure 10: Comparison of FO DTS measurement and reference profiles in the period of seepage deactivation. 


\section{DISCUSSION OF THE RESULTS, LIMITATIONS AND CONCLUSION}

Based on three independent measurement systems (control system of monitoring boreholes, BDTS and FO DTS) at the site of Vlčkovice $v$ Podkrkonoší, critical water levels in the reservoir were identified, at which crucial changes in the seepage regime of the dam take place.

During the ascent as well as descent of the seepage curve, both the BDTS and FO DTS systems showed high correlation rate with the results of the evaluation of seepage regimes by the control system, which allows for the possibility of their application for various levels of monitoring of seepage regimes in dams. However, it must be again pointed out that the installation itself has to be preceded by thoroughly performed investigative operations, sitespecific design of the spatial distribution of the sensors and subsequent pilot calibration of the system.

Based on the determined dependences, an algorithm was developed for the BDTS system as part of the project that automatically models temperature development trends at selected sensors. Based on the analysis of the degree and time of duration of the divergence between the measured and modelled development, this algorithm automatically generates three status values. The algorithm is calibrated using site-specific input parameters, which can further be specified during the operation of the system based on the gathered data.

The limitation of both systems appears at the time when the average air and water temperature trends intersect (period of the 'temperature shift' - see above). In temperate climate zones, this phenomenon occurs at least twice a year. During this time, seepage interpretation is made more difficult, if not impossible. However, for these periods there is the possibility of using heat-pulse FO DTS systems that work by analysing temperature fluctuations measured by periodically heated optical cables. These systems were also investigated in the STAMFOR project. However, the interpretation of the results exceeds the scope of this article.

Both the investigated systems feature specific advantages that determine the possibilities of their applications. Due to low investment costs, the BDTS systems can be specifically recommended for complementing and/or extending piezometer wells, while the FO DTS systems, due to their connectedness and lengths of the monitoring profiles (hundreds of meters up to several kilometres), represent an optimal solution for instances when monitoring systems are required for covering large distances or areas, such as for levees protecting areas of high-value assets or critical infrastructures.

\section{ACKNOWLEDGEMENTS}

The authors thank the E!8688 EUREKA project STAMFOR, financed by the Ministry of Education, Youth and Sports, Czech Republic and the company VODNÍ ZDROJE, a.s.

\section{REFERENCES}

[1] Normandale, D., Assessing flood defence integrity using geophysical monitoring techniques. ADA Gazette., p. 19, Winter 2016.

[2] Khan, A.A., Vrabie, V., Mars, J.I., Girard, A. \& D'Urso, G., Automatic monitoring system for singularity detection in dikes by DTS Data Measurement. IEEE Transactions on Instrumentation and Measurement, 59(8), pp. 2167-2175, 2010. DOI: 10.1109/ TIM.2009.2032880.

[3] Su, H., Kang, Y. \& Huaizhi, S., Design of system for monitoring seepage of levee engineering based on distributed optical fiber sensing technology. International Journal of Distributed Sensor Networks, 9(12), 2013. DOI: 10.1155/2013/358784. 
[4] Payat, A.L. et al., Time-frequency methods for structural health monitoring. Sensors, 14, pp. 5147-5173, 2014. DOI: 10.3390/s140305147.

[5] Balisa, B., Bartynski, T., Brzoza-Woch, R., Bubak, M., Harezlak, D. \& Kasztelnik, M., Dedicated IT infrastructure for smart levee monitoring and flood decision support. Proceedings of the FLOOD risk 2016 - 3rd European Conference on Flood Risk Management, Lyon, E3S Web of Conferences 7, 2016.

[6] Dwornik, M., Krawiec, K., Franczyk, A. \& Leśniak, A., Numerical modelling of levee stability based on coupled mechanical, thermal and hydrogeological processes. Proceedings of the FLOOD risk 2016 - 3rd European Conference on Flood Risk Management, Lyon, E3S Web of Conferences 7, 2016.

[7] Boukalová, Z. \& Beneš, V., Dike breaks prevention as the process of flooding protection. Proceedings of the International Association for Hydro-Environment Engineering and Research Congress, 32nd IAHR Congress- Venice, 2007.

[8] Boukalova, Z., Benes, V., Cejka, F. \& Hajek, T., Practical use of Geophysical monitoring system (GMS) focussed on WP3 activities. Technical report of the FP7 project FloodProBE (WP3), 2010.

[9] Čejka, F., Boukalová, Z. \& Beneš, V., Short term assessment and mitigation of flood risks in the catchment scale. WIT Transactions on Ecology and the Environment, Vol. 197, ed. C.A. Brebbia, Wessex Institute of Technology, WIT Press: Southampton and Boston, 2015. 